\title{
The Mental Health of Refugee Children in Canada
}

\author{
Ilene Hyman, Morton Beiser, and Nhi Vu
}

\begin{abstract}
This paper reviews the literature on sources of stress, and the personal and social resources refugee youth use to cope with adversity. Preliminary findings from the Clarke Institute/University. of Toronto Department of Psychiatry Southeast Asian (SEA) Refugee Youth Project, a study of the mental health and adaptation of SEA youth to Canada, are used to supplement findings from the literature. The review highlights research needs as well as possibilities for programs that could help promote the successful adaptation of refugee youth in Canada.
\end{abstract}

\section{Précis}

Cet article passe en revue la documentation décrivant les tensions vécues par les jeunes réfugiés, et les ressources individuelles et sociales dont ils disposent pour faire face d̀ l'adversité. Nous complétons les données provenant de la documentation déjà disponible à l'aide d'informations préliminaires tirées d'une étude sur la santé mentale et l'adaptation de jeunes du Sud-Est asiatique à l'environnement canadien, menée conjointement par l'Institut Clarke et le Département de Psychiatrie de l'Université de Toronto (Southeast Asian Refugee Youth Project). L'article met en relief le besoin pour des recherches plus approfondies et explore les possibilités demise sur pied de programmes qui pourraient aider a faire la promotion d'une intégration réussie des jeunes réfugiés au Canada.

Ilene Hyman, PhD., and Nhi Vu, BSc. are members of Culture, Community and Health Studies, of which Morton Beiser, MD, is Program Director, Clarke Institute of Psychiatry, Toronto.
A bout 1.5 million immigrants and refugees have come to Canada during the past decade. Seventy-five thousand were refugee children under the age of 12 . Some research literature suggests that refugee children have a higher risk than their host country counterparts of developing mental health problems such as alcohol abuse (Morgan, Wingard, \& Felice 1984), drug addiction (Amaral-Dias, Vicente, \& Cabrita 1981), delinquency and depression (Burke 1982), post-traumatic stress disorder (Kinzie 1986; Sack 1985), and psychopathology (Kinzie, Sack, \& Angell 1986). However, other studies contradict these impressions of failed adaptation. These reports document refugee children's high academic aspirations, often matched by exceptional achievement (Caplan, Choy, \& Whitmore 1992; Rumbaut \& Ima 1988).

Are the documentations of success wrong and the portrait of failure more accurate? Or are refugee children more successful than they are generally credited to be, and their mental health risks exaggerated? Is it possible that some are exceptionally accomplished, and others floundering? The last proposition is probably closest to the truth. Success or failure is not inherent in the migration or refugee situation. Research among adults demonstrates that it is the contingencies surrounding the refugee experience that determine the risk of becoming a mental health casualty, a school or vocational dropout, or a contributing member of the resettlement society (Canadian Task Force on Mental Health Issues Affecting Immigrants and Refugees 1988). These contingencies include personal strengths, the pre- and postmigration stresses and individual experiences, and the availability of family and community support.

Although a growing body of research among refugee adults supports the proposition that the contingencies surrounding the refugee experience determine outcome, few studies have explored these complex relationships among refugee youth. This paper reviews current literature on sources of stress, and the personal and social resources refugee youth use to cope with adversity. Preliminary findings from the Southeast Asian (SEA) Refugee Youth Project, a joint project of the Clarke Institute of Psychiatry and the University of Toronto Department of Psychiatry, will be used to comment upon, and supplement findings from the literature. The SEA Refugee Youth Project is a study of the mental health adaptation of SEA youth to Canada. In the study's first phase, project staff collected information from 17 in-depth individual interviews, 6 focus groups and conducted a pilot test with 102 SEA youth attending Toronto schools. The review highlights research needs as well as possibilities for programs that could help promote successful adaptation.

\section{Pre- and Post-migration Stressors Create Mental Health Risk}

Premigration traumata affect children's mental health. The natural and human-perpetrated disasters to which many refugee children are exposed create a risk for adverse psychological outcomes including depression, anxiety, anger, and psychosomatic symptoms (Kuzmic 1992; Zivcic 1993). Researchers in Montreal found that the more intense the war trauma experienced by Latin American children, the more likely they were to develop depression and anxiety (Rousseau, Corin, \& Renaud 1989).

Refugee children, many of whom witnessed violence in their homelands and experienced perilous journeys to safety, may be at high risk for post-traumatic stress disorder (PTSD), a condition marked by periodic re-ex- 
periencing of the feelings brought on by the original traumata, intrusive thoughts about the past, nightmares, distractability, hyperalertness, and emotional distancing from others. PTSD is an episodic disorder, its exacerbations usually triggered by a stimulus such as a newspaper article that activates unpleasant memories. Kinzie and Sack (Sack 1985; Kinzie \& Sack 1991) found that at least 50 percent of all Cambodian adolescent refugees attendinghigh schools in Portland qualified for a diagnosis of PTSD. A decade after Pol Pot's departure from Cambodia, nearly one fifth of a community sample of Khmer adolescents who, as children, had experienced his regime of terror, still qualified for a diagnosis of PTSD (Sack, McSharry, \& Clarke 1994).

Compared to other immigrants and to refugee adults, refugee children are more likely to have serious problems associated with malnutrition, disease, physical injuries, brain damage and sexual or physical abuse (Arroyo, Eth, \& Pynoos 1984; Westermeyer 1991). These problems may affect cognitive, social and emotional development. Freire (Freire 1989), a psychiatrist with the Toronto Board of Education, has reported that agitation, fears, focalized anxiety, emotional withdrawal and sleep disturbances are the most common symptoms among refugee children referred to mental health professionals. The mental health of refugee children has also been linked to psychiatric disorder in their parents and other family members (McCloskey \& Locke 1995; Mghir, Freed, \& Raskin 1995; Rousseau, Corin, \& Renaud 1989; Krell 1979). Parental experiences with persecution, war violence, terrorism, powerlessness and exhaustion may compromise their abilities to care for children (Hicks, Lalonde, \& Pepler, 1993). Unaccompanied refugee children are probably at higher risk for psychiatric problems than those who come to a new country as part of an intact family (Bemak \& Greenberg 1994; Bemak \& Timm 1994; Allodi 1989; Williams \& Westermeyer 1983; Westermeyer 1989).
Poverty, death of loved ones, separation from one or both parents and assaults to self-esteem constitute health risks for any child (Langner, Gersten, \& Eisenberg 1977; Rutter, Tizard, \& Yule 1976). In resettlement countries, refugee children are highly likely to experience not only poverty (Canadian Task Force on Mental Health Issues Affecting Immigrants and Refugees 1988), but interracial conflict, parental psychological distress, family instability, youth unemployment, and intergenerational conflict, each a mental health risk factor (Canadian Task Force on Mental Health Issues Affecting Immigrants and Refugees 1988; Coddington 1975; Links 1983). Disjunctures between parental and host country values and asymmetric acculturation may also affect mental health. For example, the traditional Southeast Asian pattern of restricting adolescent female freedom more than male (Kurian 1986), at the same time demanding that females accept more household responsibility, may result in clashes between familial and peer values that affect the wellbeing of Southeast Asian adolescent girls (Mogg 1991).

It has been estimated that 80 percent of adult refugees resettling in Canada speak neither English nor French on arrival (Canadian Task Force on Mental Health Issues Affecting Immigrants and Refugees 1988). Since children typically learn the resettlement country's language and customs more quickly than adults, parents often resort to using their children as translators and cultural interpreters. These families may be at risk for role reversal, with resultant destabilization of normal lines of communication and authority.

Most of the youngsters taking part in the SEA Refugee Youth Project left Southeast Asia as infants or very young children and, as a result, had little to say about premigration stressors. Many of the themes identified in the literature on post-migration stressors affecting refugee children reemerged in the interviews with the SEA sample. The research team also identified previously unreported stressors.

According to the literature, separation from parents jeopardizes mental health. The story told by an 18 year old Vietnamese woman sounds this theme with a particular poignancy.

I didn't see my father for a whole five-year period. I think those are the formative years, you come to know your parents and who they are, and what happened during those years is what determines what's going to happen later on. And I missed the whole 5 years. So when I came here, I felt like seeing a stranger right, although I loved him, he's my father, it's just that the communication wasn't there from the beginning.

Difficulty communicating with parents is a universal source of distress. This assumes many different forms, ranging from the lack of a common household language to clashes arising from differences in expectations and views about autonomy and freedom. Canadian values emphasizing freedom to express feelings openly creates problems for SEA youth in interactions with parents imbued with the expectation of emotional reticence.
Many times you see them [parents] keeping sad things to themselves, so you're sad with them, but you don't really know what it is you're sad for. With the Westerners, the parents can tell them everything, from small to big things they can talk about them all. With Vietnamese there are many things you can't talk about [19-year- old Vietnamese female].

Parental expectations for achievement constitute another source of stress. As one respondent said, "It's like pressure to be better than the rest and if you try it's not good enough." Lack of positive feedback from parents intensifies feelings of distress. According to one 18year-old Vietnamese woman:

I always find that whenever you have something good, let's say you receive high marks in school, you tell them. They're not encouraging like the parents I know that are not Vietnamese. Instead of being encouraging, they say that "you could do better." 
The sense that parents are not interested is a potent source of distress. In part, this is situational: many parents who work long hours have little time left to devote to their families. In part, this may result from an adaptive choice: SEA youth often feel reluctant to burden mothers and fathers with problems that seem unimportant compared with their parent's need to make a living in a strange country and to deal with a past filled with suffering that the children only dimly comprehend.

The clash between traditional expectations of filial piety and Canadian values emphasizing autonomy and emancipation is a major source of stress. A fifteen year old male said, "... as much as I want to go into subjects like History, I don't want to disobey him (his father) because pleasing him is everything to me." Youth want to be a source of pride, not disappointment. Several youth articulated a need to express gratitude to their parents, or to somehow repay them for the sacrifices they were making to provide a comfortable life for their children. As one 15-year-old Chinese male commented, "... because my dad and my mom have actually wasted their lives for me. And to me, if I don't give them a good life in return, I'll feel guilty for the rest of my life."

Although many youth respect their parents' values and their desire to maintain the traditional way of life, they are simultaneously attracted by Canadian values. Sometimes, they prefer what they find outside, to what they find within traditional family life. For example, they liked celebrating birthdays, a custom that was not typically practiced in SEA countries. To avoid disappointment, one young Vietnamese teen bought herself a birthday cake because she knew that her family would not. Many youth are also attracted to Canadian assumptions that it is legitimate to claim personal privacy, a concept that is at odds with the communal ideology that dominates traditional SEA family life. Most of the study participants prefer the open communication of emotions to the much more opaque methods em- ployed in Southeast Asian forms of social discourse.

Adolescence, the forging of an identity that will act as a guide for action and thought for the rest of one's life, ushers in a stress for all youth, whether immigrant or native-born, but creating an identity poses a particular challenge for refugee youth. Competition between parental and peer values coupled with larger social forces such as racism complicate the struggle to develop a coherent, valued sense of self. As one 15-year-old male said:

The fact that I'm a racial minority makes a difference. It makes my struggle a lot harder than a racial majority. I know even if I'm well educated, the fact that I'm Oriental, if you want to get into the world, it'll be harder. No matter what kind of education you get, it's going to be harder because you're a racial minority.

\section{Mental Health Protective Factors}

Despite the undeniable stresses to which they are exposed, most refugee children and youth do not become mental health casualties, but more or less successfully-adapted members of their adopted society. Personal and social resources help explain their resilience. The literature identifies two personal strengths as particularly salient for successful adaptation: the ability to speak the host country language and a secure identity (Edwards \& Beiser 1994; Hicks, Lalonde, \& Pepler 1993).

Respondents participating in the SEA Youth project agree that proficiency in English makes it easier to feel accepted and part of a community, especially at school. Quantitative analyses of the SEA youth pilot study data support their assertion. According to these data, the better one's English proficiency, the higher one's feelings of self-worth, and the poorer one's command of English, the higher the level of anxiety. According to Freire (1991), fluency in a child's first language is also important. Mother tongue fluency contributes to the development of a positive self concept, and promotes effective communication and emo- tional closeness in families. Language competence at an early age facilitates the development of competency in a second language.

An identity based, in part at least, on the culture of origin may also foster personal resilience. According to one study, immigrant children who used a native language as well as English proved to be better adjusted than children who used only English (Allodi 1989). In another study, unaccompanied Southeast Asian refugee adolescents in ethnically matched foster homes achieved higher grade point averages and developed less depression than children placed with Caucasian families (Porte \& Torney-Purta 1987). Pilot data from the Refugee Youth Project demonstrated that Canadian identity and strong ethnic pride each contribute to feelings of self worth.

The youth interviews helped identify sources of personal strength in addition to language fluency and secure identity. These included self-reliance and the ability to adapt to, and function in, a bicultural environment. In the words of a 19-year-old Vietnamese woman:

In the beginning there was no one to help. Because there was no Vietnamese in school, only Westerners. In general there was no one to help me, I had to overcome things myself. I learned to be independent when I came here.

Family and community support also contribute to successful adaptation (Fox, Cowell, \& Montgomery 1994). Refugee children separated from family members during the early years of resettlement experience increased mental health risks (Porte \& Torney-Purta 1987). A study of Latin American refugee children in Toronto found that the presence of parents, positive coping by parents, and the availability of support from the Canadian and like ethnic community each made important contributions to positive mental health (Allodi 1989). SEA refugee youth data demonstrated a positive relationship between good social support from family and feel- 
ings of self-worth. The data also suggested a negative association between the availability of family support and symptoms of depression.

In attempting to account for the exceptional academic achievement of some immigrant and refugee children, investigators have emphasized the respect for education embedded in some cultural traditions, parental ambition, and the insecurity of minority status. Although large family size has long been regarded as one of the most reliable predictors of poor achievement, Caplan, Choy, and Whitmore (1992) found a positive relation between the number of siblings in a family and Indochinese grade point averages. This reversal underlines the importance of cultural context. In majority culture families imbued with values stressing privacy and individual achievement, the presence of siblings may mean that a child has less chance of finding a private place to study, less access to parental attention and more people with whom to compete. In Southeast Asian families, it is common for everyone to sit around a kitchen table doing his or her work and each person is expected to achieve, not for personal glory, but to promote the family's reputation. In this environment siblings may contribute to, rather than impede individual success.

Children of parents with "ethnic resilience"-i.e., who, despite pressure to acculturate, maintain ethnic pride and cultural identity-perform better than children whose parents assimilate fully (Rumbaut \& Ima 1988; Rumbaut 1991).

However, the immigration experience may also constrain the family's protective and health promoting influence. Both literature and findings from the SEA Refugee Youth Project interviews suggest that communication problems and intergenerational conflict may represent significant sources of stress. Age affects the impact of intrafamilial dynamics. Children who arrive in a resettlement country as pre-adolescents, or who are born in their parent's adopted country, are more likely than children who immi- grate at an older age to adopt majority culture values. As a result, families containing adolescents who arrived as youngsters or who were born in the host country may experience more intergenerational problems than families with adolescents or young adult members who came to Canada when they were older (Mogg 1991; Sluzki 1979; Inkar 1977; Kim 1980).

The like-ethnic community, a determinant of the wellbeing of adult refugees in resettlement countries (Schrader 1986; Sion 1986; Beiser, Turner, \& Ganesan 1989), also contributes to children's self-esteem and psychological resilience (Beiser, 1988; Tran 1987). The construct of ethnic identity provides a conceptual bridge to help explain such findings. Findings of the SEA Refugee Youth Project highlight the importance of having the support of friends of a similar ethnic background.

As one 19-year-old Vietnamese female explained: "We joke around in Vietnamese and it's easier for us to understand, empathize with each other. As well, there's no bonding when hanging out with Westerners."

\section{Conclusion}

Despite the stresses they encounter along the developmental path, most children and youth in refugee families cope with the challenges of Canadian society. However, it is important to sensitize teachers and health care workers to the traumata children have endured and to their potential aftereffects. Orientation programs designed to help families identify competing intrafamilial and host country values could help alleviate resultant familial tensions. At a larger societal level, the delicate balance between supporting and respecting traditional values and community structures, while at the same time promoting the acquisition of tools to facilitate integration must be maintained. The eradication of cultural stereotypes is an important step towards accomplishing this balance.

The pursuit of these goals undoubtedly calls for the development of new programs, and for continuing research to evaluate the effectiveness of such programs as well as to pursue additional knowledge about the successpromoting factors. As a refugee-receiving country, Canada has received world acclaim. However, no country, Canada included, provides newcomers the welcome they deserve and need. Focusing on settlement, and in particular on programs and practices that protect refugee children's mental health and promote their competencies, will benefit newcomers and hosts alike.

\section{Bibliography}

Allodi, F. 1989. "The Children of Victims of Political Persecution and Torture: A Psychological Study of a Latin American Refugee Community." International Journal of Mental Health 18(2), 3-15.

Amaral-Dias, C. A., T. N. Vicente, and M. F. Cabrita. 1981. "Transplantation, Identity and Drug Addiction." Bulletin of Narcotics 33, 21-26.

Arroyo, W., S. Eth, and R. Pynoo. 1984. "Sexual Assault of a Mother by Her Preadolescent Son." American Journal of Psychiatry 141(9), 1107-108.

Beiser, M. 1988. "Influences of Time, Ethnicity, and Attachment on Depression in Southeast Asian Refugees." American Journal of Psychiatry 145, 45-51.

Beiser, M., R. J. Turner, and S. Ganesan. 1989. "Catastrophic Stress and Factors Affecting its Consequences among Southeast Asian Refugees." Social Science and Medicine 28(3), 183-95.

Bemak, F., and B. Greenberg. 1994. "Southeast Asian Refugee Adolescents: Implications for Counseling." Journal of Multicultural Counseling and Development 22(2), 115-24.

Bemak, F., and J. Timm. 1994. “Case Study of an Adolescent Cambodian Refugee: A Clinical, Developmental and Cultural Perspective." International Journal for the Advancement of Counselling 17(1), 47-58.

Burke, A. W. 1982. "Determinants of Delinquency in Female West Indian Migrants." International Journal of Social Psychiatry 28, 28-34.

Canadian Task Force on Mental Health Issues Affecting Immigrants and Refugees. 1988. After the Door Has Been Opened: Mental Health Issues Affecting Immigrants and Refugees in Canada. Ottawa: Ministry of Supply and Services Canada.

Caplan, N., M. H. Choy, and J. K. Whitmore. 1992. "Indochinese Refugee Families and 
Academic achievement." Scientific American 266, 36-42.

Coddington, R. D. 1975. "The Significance of Life events as Etiological Factors in the Diseases of Children." Journal of Psychosomatic Research 16, 205-13.

Edwards, R. G., and M. Beiser. 1994. "Southeast Asian Refugee Youth in Canada: The Determinants of Competence and Successful Coping." Canada's Mental Health 42(1), 1-5.

Fox, P. G., J. M. Cowell, and A. C. Montgomery. 1994. “The Effects of Violence on Health and Adjustment of Southeast Asian Refugee Children: An Integrative Review." Public Health Nursing 11(3), 195-201.

Freire, M. 1989. "Refugee Families and their Children." Paper presented at the International Symposium on The Refugee Crisis: British and Canadian Response. Oxford University, UK.

Freire, M. 1991. "Immigrant and Refugee Children: Native Language as a Factor in the Development of the Self and the Competent Acquisition of a Second Language." Paper presented at Conference Better Beginnings Better Futures Project. Immigrant and Refugee Children: Development Research Symposium Communities and Social Services, Health Education and Indian and Native Affairs Ministries. Toronto.

Hicks, R., R. N. Lalonde, and D. Pepler. 1993. "Psychosocial Considerations in the Mental Health of Immigrant and Refugee Children. Special Issue: Cultural Diversity: Voice, Access, and Involvement. Canadian Journal of Community Mental Health 12(2), 71-87.

Inkar, M. 1977. "Immigration and Learning: The Vulnerable Age." Canadian Review of Sociology and Anthropology 14, 218-34.

Kim, B. K. 1980. "Attitudes, Parental Identification, and Locus of Control of Korean, New Korean-Canadian and Canadian Adolescents." In Visible minorities and Multiculturalism: Asians in Canada, edited by K. V. Ujimoto and G. Hirabayashi, 219-42. Toronto: Butterworths.

Kinzie, J. D. 1986. "Severe Post-Traumatic Strèss Syndrome among Cambodian refugees: Symptoms, clinical course, and treatment approaches." In Disaster Stress Studies: New Methods and Findings, edited by J. H. Shore, 124-40. Washington: American Psychiatric Press.

Kinzie, J. D., and W. H. Sack. 1991. "Severely Traumatized Cambodian Children: Research Findings and Clinical Implications." In Refugee Children: Theory, Research, and Services, edited by F. L.
Ahearn and J. L. Athey, 92-105. Baltimore: Johns Hopkins University.

Kinzie, J. D., W. H. Sack, and R. H. Angell. 1986. “The Psychiatric Effects of Massive trauma on Cambodian Children: I. The Children." Annual Meeting of the American Academy of Child Psychiatry 1984, Toronto, Canada. Journal of the American Academy of Child Psychiatry 25(3), 370-76.

Krell, R. 1979. "Holocaust Families: Survivors and Their Children." Comprehensive Psychiatry 20, 560-68.

Kurian, G. "Socialization of South Asian Youth in Canada." In Anonymous. Paper. presented at the International Sociology Association Conference.

Kuzmic, D. 1992. "Psychic Reactions to War in Children of Soldiers and Refugees." Psychologische Beitrage 34(3-4), 206-14.

Langner, G. S., J. Gersten, and J. Eisenberg. 1977. "The Epidemiology of Mental Disorder in Children: Implications for Community Mental Health." In New Trends of Psychiatry in the Community: Proceedings of the Fourth International Symposium of the Kittay Scientific Foundation, edited by G. Serban, 69-110. Cambridge, Ma.: Ballinger.

Links, P. S. 1983. "Community Surveys of the Prevalence of Childhood Psychiatric Disorders: A Review." Child Development 54, 531-48.

McCloskey, L., and C. Locke. 1995. "The Psychological Effects of Political and Domestic Violence on Central American and Mexican Immigrant Mothers and Children." Journal of Community Psychology 23(2), 95-116.

Mghir, R., W. Freed and A. Raskin. 1995. "Depression and Post-traumatic Stress Disorder among a Community Sample of Adolescent and Young Adult Afghan Refugees." Journal of Nervous \& Mental Disease 183(1), 24-30.

Mogg, J. M. 1991. “The Experience of Bicultural Conflict by Vietnamese Adolescent Girls in Greater Vancouver." Unpublished master's thesis, Simon Fraser University, Vancouver, $B C$.

Morgan, M. C., D. L. Wingard, and M. C. Felice. 1984. "Subcultural Differences in Alcohol Use among Youth." Journal of Adolescent Health Care 5, 191-95.

Porte, Z., and J. Torney-Purta. 1987. "Depression and Academic Achievement among Indochinese Refugee Unaccompanied Minors in Ethnic and Non-ethnic Placements." American Journal of Orthopsychiatry 57(4), 536-47.

Rousseau, C., E. Corin, and C. Renaud. 1989. "Armed Conflict and Trauma: A Clinical Study of Latin-American Refugee Chil- dren." [French]. Canadian Journal of Psychiatry-Reoue Canadienne de Psychiatrie 34(5), 376-85.

Rumbaut, R. G. 1991. “The Agony of Exile: A Study of the Migration and Adaptation of Indochinese Refugee Adults and Children. In Refugee Children: Theory, Research, and Services, edited by F. L. J. Ahearn and J. L. Athey, 53-91. Baltimore: The Johns Hopkins University Press.

Rumbaut, R. G., and K. Ima. 1988. The Adaptation of Southeast Asian Refugee Youth: $A$ Comparative Study. Washington: United States Office of Refugee Resettlement.

Rutter, M., J. Tizard, and W. Yule. 1976. "Research Report: Isle of Wight Studies, 1964-1974." Psychological Medicine 6, 31332.

Sack, W. H. 1985. "Post-traumatic Stress disorders in Children." Integrative Psychiatry $3,162-64$.

Sack, W. H., S. McSharry, and G. N. Clarke. 1994. "The Khmer Adolescent Project. I. Epidemiologic Findings in Two Generations of Cambodian Refugees." Journal of Nervous \& Mental Disease 182(7), 387-95.

Schrader, A. 1986. "The Vulnerable Age: Findings on Foreign Children in Germany." Social Education 51, 227-30.

Sion, R. J. 1986. "Refugee Women and Their Daughters: A Comparison of Soviet, Vietnamese and Native-born American Families." In Refugee Mental Health in Resettlement Countries, edited by C. A. Williams and J. Westermeyer. 157-174. Washington: Hemisphere.

Sluzki, C. E. 1979. "Migration and Family Conflict." Family Process 18, 379-90.

Tran, T. V. 1987. "Ethnic Community Supports and Psychological Wellbeing of Vietnamese Refugees." International Migration Review 21, 295-99.

Westermeyer, J. 1989. Mental Health for Refugees and Other Migrants: Social and Preventative Approaches. Springfield, IL: Charles C. Thomas.

- 1991. "Psychiatric Services for Refugee Children: An Overview." In Refugee Children, edited by F. L. Ahearn and J. L. Athey, 127-62. Baltimore, MD: Johns Hopkins University Press.

Williams, C. L., and J. Westermeyer. 1983. "Psychiatric Problems among Adolescent Southeast Asian Refugees." Journal of Neroous and Mental Disease 171,79-85.

Zivcic, I. 1993. "Emotional Reactions of Children to War Stress in Croatia." Journal of the American Academy of Child \& Adolescent Psychiatry 32(4), 709-13. 